\title{
Possible Therapeutic Potential of Cysteinyl Leukotriene Receptor Antagonist Montelukast in Treatment of SARS-CoV-2-Induced COVID-19
}

\author{
Mangaldeep Dey Rakesh Kumar Singh \\ National Institute of Pharmaceutical Education and Research, Department of Pharmacology and Toxicology, \\ Raebareli, Transit campus, Lucknow, India
}

\section{Keywords}

Severe acute respiratory syndrome virus $2 \cdot$ Coronavirus disease-19 - Montelukast · Remdesivir · Cytokine storm . Antiviral drug

\begin{abstract}
Background: The coronavirus disease-19 (COVID-19) pandemic is a serious devastating disease and has posed a global health emergency. So far, there is not any specific therapy approved till date to control the clinical symptoms of the disease. Remdesivir has been approved by the FDA as an emergency clinical therapy. But it may not be effective alone to control the disease as it can only control the viral replication in the host. Summary: This article summarizes the possible therapeutic potential and benefits of using montelukast, a cysteinyl leukotriene 1 (Cys $\mathrm{LT}_{1}$ ) receptor antagonist, to control COVID-19 pathophysiology. Montelukast has shown anti-inflammatory effects, reduced cytokine production, improvement in post-infection cough production and other lung complications. Key Messages: Recent reports clearly indicate a distinct role of CysLT-regulated cytokines and immunological signaling in COVID-19. Thus, montelukast may have a clinical potential to control lung pathology during COVID-19.

(c) 2021 S. Karger AG, Basel
\end{abstract}

The recent severe advent of the coronavirus disease-19 (COVID-19) pandemic caused by severe acute respiratory syndrome virus 2 (SARS-CoV-2) has posed a global public health emergency [1-3]. Despite a large number of preventive measures, the potential contagious nature of SARSCoV-2 has led to a much faster human-to-human transmission and serious mortality rate $[4,5]$. The children are least affected, showing milder or even asymptomatic infection. However, the disease has more severity in older agegroup, with a death rate of $14.8 \%$ above 80 years [6, 7]. In addition, the severity of COVID-19 and subsequent mortality rates are higher in patients with pre-existing diseases such as with chronic respiratory diseases, cardiovascular diseases, diabetes, and cancer $[8,9]$. The present therapeutic strategies to combat SARS-CoV-2 infection are nonspecific, symptomatic, and supportive. The current therapies used to control the pathophysiology of COVID-19 patients include antiviral drugs, antibiotics, glucocorticoids, and mechanical ventilation [10-12]. However, there is no specific therapy approved for the treatment of COVID-19 so far. Therefore, a specific and effective therapeutic strategy is urgently needed to reduce the severity and mortality due to SARS-CoV-2 infection. 
Serious extensive efforts are being made by researchers for identification of small molecules/biologicals for engagement of novel therapeutic targets. However, such drug discovery approach is challenging and time-consuming. Therefore, the drug repurposing approach may be one of the best possible options to rapidly identify an effective therapy for improvement in clinical outcomes of severe COVID-19 patients [13, 14].

Notably, recent information have revealed a role of elevated levels of cysteinyl leukotrienes (CysLTs) in regulation of vascular leakage, edema, and cytokine signaling in immune cells such as macrophage and lymphocytes [15, 16]. The role of these lipid mediators in the pathophysiology of COVID-19 seems to be logical, and serious efforts are being made to evaluate the effect of montelukast, a CysLT $_{1}$ receptor antagonist, in COVID-19 [17-19]. Montelukast is one of the approved and marketed drugs for asthma in children and adults. Several in vitro and in vivo studies have pointed toward the potential mechanism of action of montelukast against different viruses, which can be potentially applied to SARS-CoV-2 induced COVID-19. The lung alveolar macrophages are the first line of defense against lower respiratory tract infections. During infection, the lethal lung injury occurs due to elimination of the infected type-1 alveolar epithelial cells by effector T cells [20]. Moreover, $\mathrm{LTD}_{4}$ production by type- 1 alveolar epithelial cells may enhance cellular uptake and replication of virus by signaling through $\mathrm{CysLT}_{1}$ receptors [21]. The alveolar macrophages positively regulate type-1 alveolar epithelial cells by suppression of $\mathrm{LTD}_{4}$ production [22]. Montelukast and other $\mathrm{CysLT}_{1}$ receptor antagonists can protect against influenza A virus-induced pneumonia by reducing infection of type- 1 alveolar epithelial cells and modulating $\mathrm{CysLT}_{1}$ receptor signaling [22]. In addition, it also inhibited expression of the viral genome in influenza A virus [23]. This drug has recently shown antiviral activity against dengue and Zika viruses [24] and acts by producing irreversible damage to the lipid membrane and viral genome, leading to early inactivation of dengue and Zika viruses [24], a dose-dependent decrease in the level of RNA expression leading to inhibition of viral replication [25]. Furthermore, it has also been reported to show antiviral properties in animal models to attenuate respiratory syncytial virus infection [26]. It has been suggested that montelukast can have a protective effect in virus-induced airway inflammation in the lungs [27]. Interestingly, the severity and progression of SARSCoV-2 infection are thought to be related to excessive increase in pro-inflammatory cytokine levels [28]. Thus, montelukast may have anti-inflammatory activity against
SARS-CoV-2 and may also act as an antiviral agent by the modulation of innate and adaptive immunity [28].

This review article provides a systematic analysis of the recent advancements in the understanding of molecular mechanisms of montelukast, a CysL $\mathrm{T}_{1}$ antagonist in COVID-19 (Fig. 1). It also aims to highlight the possible clinical advantages of repurposing montelukast to control the SARS-CoV-2 infection-associated lung pathophysiology in COVID-19.

\section{CysLTs and Its Receptor Signaling in Pathogenesis of SARS-CoV-2 Infection}

The SARS-CoV-2 is an enveloped, single and positive stranded RNA virus. The virus consists of 4 structural proteins: spike $(\mathrm{S})$ protein, envelope $(\mathrm{E})$ protein, membrane $(\mathrm{M})$ protein, and nucleocapsid $(\mathrm{N})$ proteins [29]. The entry of SARS-CoV-2 into the host cells is mediated by interaction between the viral spike protein and host angiotensin-converting enzyme 2 receptor cell surface proteins $[8,30]$. After entry into the host cell, the virus releases RNA, translates its RNA replicase, and forms an RNA replicase-transcriptase complex $[9,30]$. This complex forms the viral structural proteins through transcription, replication, and combined with RNA in the cytoplasm to assemble new viral particles [29]. The replicated viral particles are released from infected cells by exocytosis and eventually spread to bronchi, alveoli, and extrapulmonary organs $[14,30]$. Thus, SARS-CoV-2 spreads primarily in the lung, in addition to other organs, causing lung complications such as pneumonia, infections, and multi-organ failure in severe stages of COVID-19 [31].

In addition to the direct pathogenesis caused by the virus, the indirect immune activation is also responsible for the severity and mortality associated with COVID-19 [25]. Leukotrienes (LTs) and CysLTs are considered one of the prime candidates involved in modulation of hyper-inflammatory responses in COVID-19 progression [16]. The term CysLT includes $\mathrm{LTC}_{4}, \mathrm{LTD}_{4}$, and $\mathrm{LTE}_{4}$, and they are structurally different from $\mathrm{LTA}_{4}$ and $\mathrm{LTB}_{4}$, which are commonly known as LTs. The 2 main receptors for CysLTs are CysLT $\mathrm{T}_{1}$ and $\mathrm{CysLT}_{2}$ receptors, whereas $\mathrm{LTB}_{4}$ mainly binds to $\mathrm{BLT}_{1}$ and $\mathrm{BLT}_{2}$ receptors [32-34]. $\mathrm{LTB}_{4}$ has been reported to be one of the key chemoattractant for neutrophils and lymphocytes in SARS-CoV-2-infected airways. This ultimately may lead to profound blood lymphocytopenia in addition to neutrophilia, observed in the airways of COVID-19 patients. The CysLTs including $\mathrm{LTC}_{4}$ and $\mathrm{LTD}_{4}$, are distinctly involved in mediating vascular leakage 


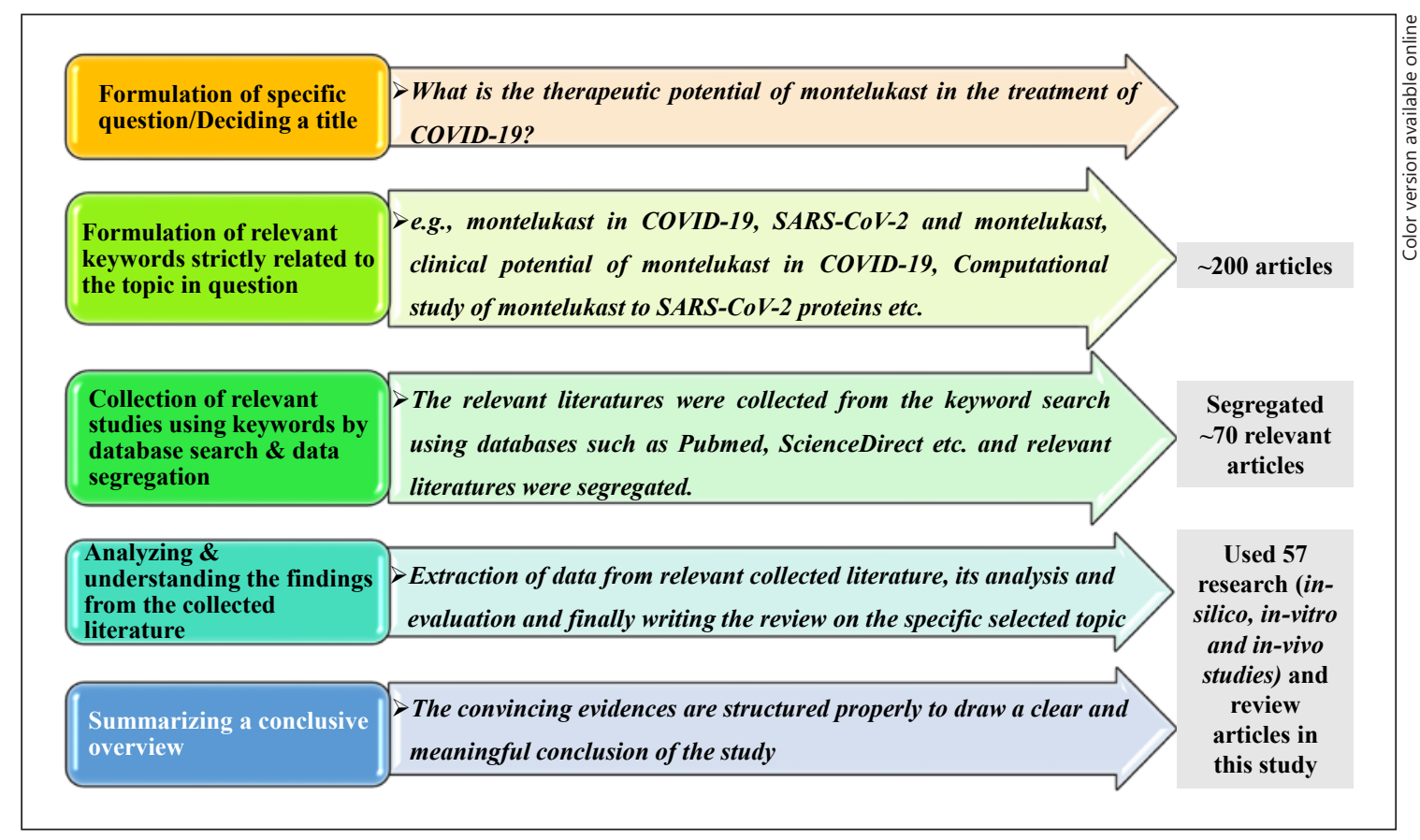

Fig. 1. Process of systematic literature review used for the study. COVID-19, coronavirus disease-19; SARA$\mathrm{CoV}-2$, severe acute respiratory syndrome virus 2 .

through CysLT $\mathrm{T}_{1}$ and CysLT 2 receptors. They also modulate hyperactivation of immunological cells such as macrophages leading to cytokine release and nuclear factor kappa-light-chain enhancer of activated B cells (NF- $\kappa B$ ) activation $[35,36]$. These actions of LTs and CysLTs may contribute to the development of cytokine storm in COVID-19. However, there are only limited studies done to decipher the role of CysLTs in the pathophysiology of COVID-19. This might be because of several reasons [16]: (i) The CysLTs cannot be easily measured as compared to the cytokines regulated by them; (ii) They undergo rapid physiological metabolism and are not much stable due to their chemical nature; (iii) There have been only two specific clinical therapies (zileuton, 5-lipoxygenase inhibitor, and montelukast - a CysLT ${ }_{1}$ receptor antagonist) available in this class even after three decades of extensive research [34]. So, it might be difficult to develop successful therapies in this class.

Recent reports have suggested that lung tissue injury and pulmonary inflammation in COVID-19 patients showed a significant increase in pro-inflammatory cytokine levels (such as interleukin [IL]-1 $\beta$, IL-6, IL-12, IFN- $\gamma$, IP-10, and MCP-1) in serum [37, 38]. The SARS-CoV-2 host entry is recognized by pattern recognition receptors (PRRs) in the host immune system. Such pattern recognition receptors include toll-like receptors TLRs, C-type lectin-like receptors, RIG-1 like receptors, and NOD-like receptor [39]. The activation of these pathways leads to expression of inflammatory markers that prevent phagocytosis of the viral antigens by host macrophages [40]. The viral N-protein of SARS-CoV is linked to protect the virus against the immune system [14]. $\mathrm{CD} 4^{+} \mathrm{T}$ and $\mathrm{CD} 8^{+} \mathrm{T}$ cells play an important role in maintaining the host adaptive immune response [41]. $\mathrm{CD}^{+} \mathrm{T}$ cells stimulate the $\mathrm{B}$ cells to promote the formation of antibodies, while $\mathrm{CD}^{+} \mathrm{T}$ cells directly kill the virus-infected cells [41]. Hyper-exaggerated immune response induces free radical injury to various organs, especially in the lungs and lymphoid tissues, resulting in multiorgan failure and death [42]. This immunological hyperactivation leads to cytokine storm in the patients. Autopsy studies have shown a destruction of the lymphoid tissue and low counts of $\mathrm{CD}^{+} \mathrm{T}$ cells and $\mathrm{CD} 8^{+} \mathrm{T}$ cells in severe COVID-19 patients with cytokine storm $[41,43-45]$. NF- $\kappa B$ is known to be a key player in inflammatory responses and is a rapidly translated protein in response to viral infections [40]. NF- $\kappa \mathrm{B}$ is a key protein complex involved in cytokine production during SARS-CoV-2 infections [25]. The inhibition of the NF- $\kappa B$ signaling pathway has been explored for its therapeutic potential in inflammatory diseases due to its key regulatory role in cytokine production $[37,46]$. 


\section{Role and Molecular Mechanism of Montelukast in Management of Lung Pathology in COVID-19}

It has been reported that severe COVID-19 patients demonstrate a hyper-inflammatory condition, possibly due to a dysregulated cytokine response. The COVID-19 patients in the ICU have shown high levels of CysLTs and cytokines in plasma as compared with non-ICU patients. This suggests that dysregulated release of CysLTs and cytokines are important aspects in the severe form of COVID-19 [3, 47]. Additionally, SARS-CoV-2-infected patients have displayed a significant increase in the levels of GM-CSF, IL-6, and CD4 $4^{+} \mathrm{T}$ cells $[45,48]$. The inhibition of these exaggerated inflammatory cytokine responses may reduce COVID-19 severity.

Montelukast is one of the FDA-approved anti-asthma drugs and is a CysLT 1 receptor antagonist with distinct selectivity and specificity. It elicits anti-inflammatory effects by inhibition of NF- $\kappa B$ signaling and oxidative stress $[16,27,28]$. The inhibition of NF- $\kappa \mathrm{B}$ signaling leads to a significant reduction in the levels of pro-inflammatory mediators (IL-6, IL-8, IL-10, TNF- $\alpha$, and MCP-1) [49]. In addition to this, montelukast increased antioxidant enzyme levels (glutathione and superoxide dismutase) and lowered mortality in animal models of lung inflammation $[46,50]$. The activation of eosinophils and lung epithelial cells can increase the synthesis of CysLTs [51]. Furthermore, Th2 cytokines including IL- 4 and IL-5 activate eosinophil release and can upregulate synthesis and release of CysLTs, respectively. The administration of montelukast in vivo prevented inflammatory protein expression in the lung through the suppression of T-helper type-2 cytokines (IL-4, IL-5, and IL-13), particularly in eosinophils [51]. Treatment with montelukast could significantly reduce the levels of IL-4, IL-5, and IL- 6 but increase the levels of IFN- $\gamma$ and IL-10 [27, 52]. This effect ultimately leads to regulate Th1/Th2 balance, leading to increased level of $\mathrm{CD}^{+} \mathrm{CD}^{2} 5^{+}$regulatory T cells $[24,28,50]$. Montelukast can inhibit the accumulation and proliferation of eosinophilic and other inflammatory cells, reduce the glandular secretion of mucus in airway, and affect activation and differentiation of lymphocytes in vivo [49]. The CysLT $_{1}$ receptors present in the lung are involved in increased permeability of blood vessels leading to lung edema leading to structural changes such as airway remodeling and fibrosis [53]. Hence, the net result of all these effects of montelukast is reduced permeability of blood vessels due to inhibition of CysLTs, in addition to angiogenesis inhibition in the lung, leading to an improvement of lung fibrosis and airway remodeling [27]. Thus, mon- telukast acts as an anti-inflammatory agent in lung diseases and has been shown to effectively improve lung functions.

It has been demonstrated that after the onset of SARS$\mathrm{CoV}-2$ infection, $\mathrm{CD} 4+\mathrm{T}$ cells are activated to produce GM-CSF and other inflammatory cytokines, thus resulting in further induction of $\mathrm{CD} 14^{+} \mathrm{CD} 16^{+}$monocytes with high expression of IL-6 [52]. This observation leads to the possibility that blocking IL-6 receptors could potentially reduce immune stress caused by SARS-CoV-2 [52]. In line with this observation, a multicenter, randomized, controlled clinical trial is currently underway using an IL-6 receptor-specific antibody, tocilizumab (https:// www.clinicaltrials.gov/ct2/show/NCT04317092). Since montelukast has been shown to reduce IL-6 levels in clinical studies with bronchial asthma patients [51], its therapeutic use in COVID-19 patients may improve the severity of SARS-CoV-2 infections. Montelukast also controls the frequency and severity of wheezing in patients with clinical episodic wheezing, caused by influenza virus, corona virus, and adenovirus $[50,54]$. The clinical use of montelukast in these patients may control the cytokine storm and a positive improvement of lung function (Fig. 2). This may further improve clinical outcomes in severe COVID-19 patients. Therefore, repositioning of montelukast to attenuate pro-inflammatory signaling would be an effective therapeutic strategy for COVID-19 patients.

Several computational studies have checked the binding of montelukast to the main protease $\left(\mathrm{M}_{\text {pro }}\right)$ or 3-chymotrypsin-like protease $\left(\mathrm{CL}_{\mathrm{pro}}\right)$ of SARS-CoV-2 [28, 50, $55,56]$. This is because $\mathrm{M}_{\text {pro }}$ or $\mathrm{CL}_{\text {pro }}$ acts as a catalyst for maturation of viral protein assembly and is the main protease responsible for viral replication. Copertino et al. [50] performed in silico molecular docking analysis to simulate binding of montelukast to catalytically active sites within SARS-CoV-2 $\mathrm{M}_{\text {pro }}$ and RNA-dependent RNA polymerase (RdRp). Remarkably, montelukast showed low binding energy on binding to catalytic site of either $\mathrm{M}_{\mathrm{pro}} / \mathrm{CL}_{\text {pro }}$ or RdRp, suggesting a probable drug protein interaction between montelukast and $\mathrm{M}_{\text {pro }}$ or RdRp $[50,55,56]$. Another in silico study targeting the SARS-CoV-2 $\mathrm{M}_{\text {pro }}$ reported the binding of montelukast with two potential binding sites in the central and terminal region of the main substrate-binding pocket of $M_{\text {pro }}$ $[18,50,56]$. These studies have predicted a high affinity of montelukast for its perfect fit into the active pockets of the binding domains of $\mathrm{M}_{\text {pro }}$ enzyme with hydrophobichydrophobic and hydrogen bond interactions [55]. Since $\mathrm{M}_{\text {pro }}$ is involved in the maintenance of viral protein as- 
Fig. 2. Possible mechanistic role of montelukast in modulation of SARS-CoV-2-induced COVID-19. The various pathological consequences brought about by SARS$\mathrm{CoV}-2$ can be controlled by administration of montelukast (blue dotted line). In addition, montelukast has also been hypothesized to inhibit viral replication as evidenced by in silico binding affinity to main protease of SARS-CoV-2. COVID-19, coronavirus disease-19; SARA-CoV-2, severe acute respiratory syndrome virus 2; NF- $\kappa \mathrm{B}$, nuclear factor kappa-light-chain enhancer of activated B cells; IL, interleukin; CysLT, cysteinyl leukotriene.

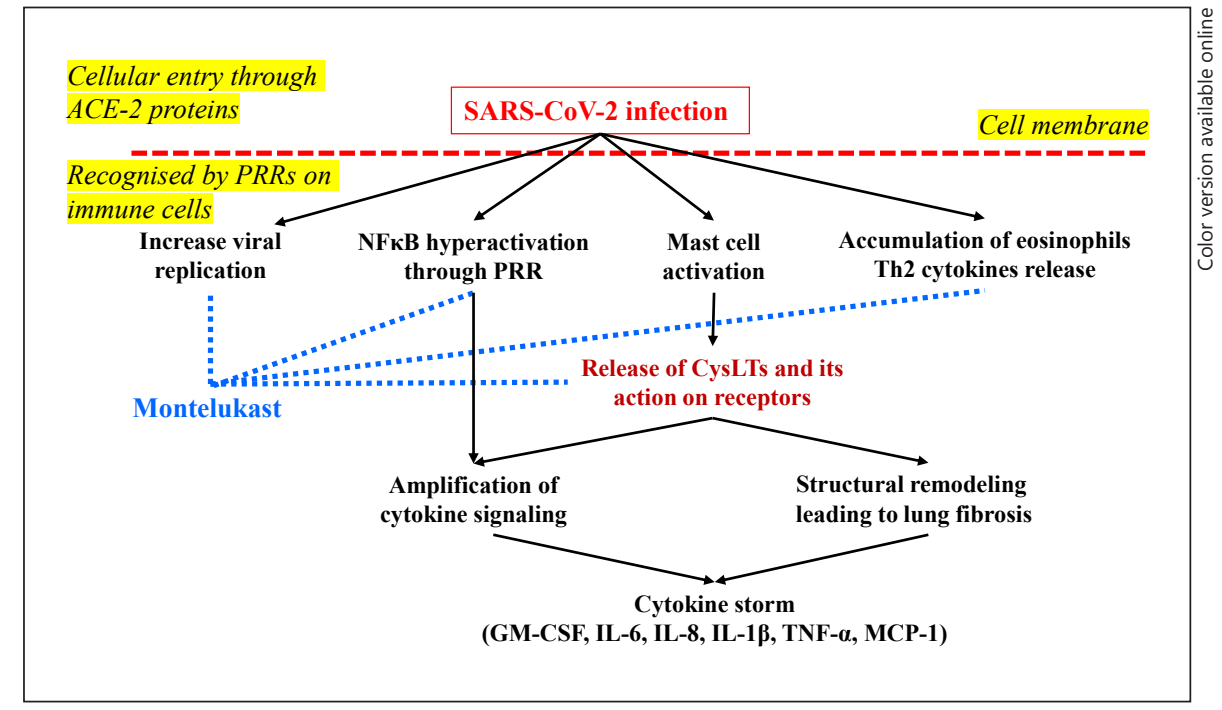

sembly and its maturation leading to viral replication, montelukast would cause the inhibition of SARS-CoV-2 replication by binding to $\mathrm{M}_{\text {pro }}[28,55]$. Thus, montelukast may have the ability to modulate the COVID-19 pathology by virulence silencing of SARS-CoV-2 [55, 56]. These computational findings highlight a robust antiviral potential of montelukast. This antiviral activity of montelukast could effectively be complemented by its clinically established anti-inflammatory effects exerted by blockade of CysLT ${ }_{1}$ receptors and inhibition of cytokine expression in activated macrophages.

The ability of montelukast to reduce the risk of COVID-19 infection was assessed in several interesting retrospective observational clinical study $[18,19]$. This study was done on elderly severe asthma patients, already treated with montelukast for 12 months. These patients were also treated previously with inhalational glucocorticoids and long-lasting beta-agonists in order to better control the asthmatic episodes of severe cases [18]. The age, associated comorbidities, other anti-asthmatic therapies, and social profile of the patients included in the study were similar. The results of this study showed that the occurrence of COVID-19 cases [18] and lung function deterioration [19] among the montelukast-treated patients were significantly reduced as compared to the nonmontelukast group $[18,19]$.

Based on these evidences, montelukast is currently in phase III clinical trials with an overall objective to study (https://clinicaltrials.gov/ct2/show/NCT04389411) its efficacy in reducing the severity of COVID-19 symptoms. Another recent clinical study is also under trial (https://
clinicaltrials.gov/ct2/show/record/NCT04714515) to determine the efficacy of montelukast alone and in combination with either ivermectin or hydroxychloroquine or both. Thus, montelukast may be helpful to serve as a therapeutic drug for alleviating severe lung complications such as ARDS and cytokine storm syndrome in COVID-19 [17] in addition to disruption of viral replication (Fig. 2).

\section{Potential Therapeutic Advantage of Montelukast with Antiviral, Antibiotic, and Anti-Inflammatory Combination Therapy in COVID-19}

The understanding of the COVID-19 pathophysiology so far suggests that an antiviral therapy alone may not be able to control the severity and high mortality rate in advanced stages of the disease [11]. It has been well-documented that there is an exaggerated immune response leading to cytokine storm in COVID-19 patients [25]. In addition, the cytokine storm has been found to be associated with increased severity and mortality in COVID-19 [47]. Therefore, the clinical use of an anti-inflammatory agent, such as montelukast along with other relevant therapies (antiviral, antibacterial, and anti-inflammatory), may have a successful potential to control COVID-19 severity and mortality.

Another comparative clinical study has evaluated the effectiveness of a multidrug therapy including montelukast in combination with ivermectin, azithromycin, and acetylsalicylic acid in SARS-CoV-2 (18- to 80-year-old patients receiving ambulatory care at Tlaxcala, Mexico Min- 
istry of Health of Tlaxcala) patients. Nearly $85 \%$ of patients receiving these combination therapy recovered within 14 days, and $>75 \%$ had lower risk of being hospitalized or death than the comparison group. However, these patients had a significantly lower prevalence of comorbidities. Ivermectin is highly capable of reducing viral replication of RNA viruses through protein inhibition $[57,58]$. In addition, it also modulates the host's immune system by increasing C-reactive protein levels, reducing the production of TNF- $\alpha$ and IL- 6 , as well as the activation of neutrophils. Due to these reasons, ivermectin displayed effective response in the nonsevere clinical stages of COVID-19 [58]. Antibiotics such as azithromycin have shown anti-inflammatory and immunomodulatory effects against viral infections and can be a useful treatment during the mild and moderate stages of SARS-CoV-2 infection [59-61]. During the acute phase of SARS-CoV-2 infection, azithromycin may regulate and reduce the production of pro-inflammatory cytokines (TNF- $\alpha$, IL-1 $\beta$, and IL-6). It has shown inhibition of viral replication against other coronavirus types both in vitro and in vivo [60]. In addition, azithromycin works favorably in vitro to prevent co-infection by bacterial agents and SARS-CoV-2 in the lung parenchyma [59]. The cytokine storm triggered by SARS-CoV-2 infection may cause a state of hypercoagulability and platelet hyperaggregation, leading to venous and arterial thrombosis and microvascular thrombosis [62]. Hence, acetylsalicylic acid has been used as an anti-inflammatory and antithrombotic medication in these patients. Since montelukast effectively exerts its anti-inflammatory effect in vivo by suppressing Th2 cytokines (IL-4, IL-5, and IL-13) in the lungs in addition to the bronchodilator effect, secondary to its interaction with $M_{\text {pro }}$ of SARS-CoV-2 virus [18, 28, 50, 56]; hence, a combination of montelukast with these drugs may have a significant therapeutic potential in reduction of SARS-CoV-2 infection $[17-19,56]$.

On similar lines, a study using Janus kinase inhibitor (baricitinib) in combination with remdesivir is being explored in phase III clinical trials (clinicaltrials.gov/ct2/ show/NCT04401579) to examine the potential of combination therapy for improvement in clinical outcomes of COVID-19. These ongoing studies provide an initial proof of concept for the proposed repurposing potential of montelukast. Montelukast has already been in market for several years now and is a low-cost drug. It is specifically marketed drug for management of lung diseases such as acute asthma and bronchial hyperactivation [27, 46]. Several reports have indicated that montelukast is effective in reducing the pro-inflammatory cytokine signaling and hence may be useful to control the cytokine storm in CO-
VID-19 [17-19, 28]. These results are positively hopeful and point toward promising use of montelukast alone or in combination with antibiotics, antivirals, or other antiinflammatory drugs in SARS-CoV-2-induced COVID-19.

\section{Possible Limitations of Montelukast Therapy}

The safety profile of montelukast is clinically established and found to be good with rare chances of drugdrug interactions. However, it has been reported that coadministration of montelukast with cytochrome P450 inducers (such as phenobarbital and rifampicin) require specific attention, as it may significantly reduce the bioavailability of montelukast. Apart from this, the FDA has issued a boxed warning issue for use of montelukast, considering its associated neuropsychiatric side effects (anxiety, sleep disturbances, depressive episodes, and suicidality). However, this effect may also be due to an inflammatory response and neurological imbalances in the hippocampus evident in the disease pathology. Besides these, so far, there are not any other issues reported with clinical use of montelukast [63].

\section{Conclusion and Summary}

Currently, the COVID-19 pandemic has presented a major global public health disaster. The solemnity and continuous efforts of researchers, pharmaceutical industries, and health authorities across the world highlight the need of the hour. Serious efforts are ongoing to find compounds and drugs that can decrease COVID-19 progression. Several clinical trials are launched at a faster pace to investigate potential therapies for COVID-19. However, despite all these efforts, there has not been any effective therapy so far, and it remains a global challenge for scientific community.

Recent reports have clearly provided a rationale for the role of LTs in COVID-19 pathogenesis [10, 16-18]. The urinary $\mathrm{LTE}_{4}$ levels can be selected as a robust biomarker and can be checked in mild to severe form of COVID-19 patients in order to further establish the role of CysLTs in the disease [16]. Indeed, the available reports so far provide a distinct scientific basis for use of montelukast either alone or in combination with antiviral therapy to control severe forms of COVID-19 [15, 56]. In addition, montelukast has been predicted to bind to $\mathrm{M}_{\text {pro }}$ of SARS$\mathrm{CoV}-2$ and could also add with remdesivir to block viral replication. Thus, the use of montelukast therapy in CO- 
VID-19 patients prior to outburst of cytokine storm may be an effective approach to control the disease.

Since the discovery of a new drug is a time-consuming process, the drug repurposing approach should be broadened. A combination of drugs acting through different therapeutic targets should be evaluated in COVID-19 patient trials to effectively control the disease. Recent convincing pieces of evidence have proposed the possible use of montelukast to control the pathophysiological effects of elevated CysLTs and resulting vascular leakage and cytokine storm in severe forms of COVID-19. Importantly, montelukast has already been approved for human use and is a safer alternative for clinical use either alone or in combination with antiviral drugs and may prove to be promising.

\section{Conflict of Interest Statement}

The authors report no conflict of interest.

\section{Funding Sources}

The authors receive no funding in preparing the manuscript.

\section{Author Contributions}

Mangaldeep Dey has prepared the first draft of the manuscript. Rakesh Kumar Singh has conceptualized and revised the manuscript for submission to the journal.

\section{References}

1 Wang L, Wang Y, Ye D, Liu Q. Review of the 2019 novel coronavirus (SARS-CoV-2) based on current evidence. Int J Antimicrob Agents. 2020;55(6): 105948

2 Wu F, Zhao S, Yu B, Chen YM, Wang W, Song ZG, et al. A new coronavirus associated with human respiratory disease in China. $\mathrm{Na}$ ture. 2020;579:265-9.

3 Xie P, Ma W, Tang H, Liu D. Severe COVID-19: a review of recent progress with a look toward the future. Front Public Health. 2020;8:189.

4 Lai J, Ma S, Wang Y, Cai Z, Hu J, Wei N, et al. Factors associated with mental health outcomes among health care workers exposed to coronavirus disease 2019. JAMA Netw Open. 2020;3(3):e203976.

5 Olsen SJ, Chen MY, Liu YL, Witschi M, Ardoin A, Calba C, et al. Early introduction of severe acute respiratory syndrome coronavirus 2 into Europe. Emerg Infect Dis. 2020; 26(7):1567-70.

6 Kang SJ, Jung SI. Age-related morbidity and mortality among patients with COVID-19. Infect Chemother. 2020;52(2):154-64.

$7 \mathrm{Wu}$ Z, McGoogan JM. Characteristics of and important lessons from the coronavirus disease 2019 (COVID-19) outbreak in China: summary of a report of 72,314 cases from the Chinese center for disease control and prevention. JAMA. 2020;323(13):1239-42.

8 Al-Tameemi K, Kabakli R. Novel coronavirus (2019-NCoV): disease briefings. Asian J Pharm Clin Res. 2020;13(5):22-7.

9 Arabi YM, Murthy S, Webb S. COVID-19: a novel coronavirus and a novel challenge for critical care. Intensive Care Med. 2020;46(5): 833-6.

10 Altay O, Mohammadi E, Lam S, Turkez H, Boren J, Nielsen J, et al. Current status of COVID-19 therapies and drug repositioning applications. iScience. 2020;23(7):101303.
11 Chibber P, Haq SA, Ahmed I, Andrabi NI, Singh G. Advances in the possible treatment of COVID-19: a review. Eur J Pharmacol. 2020;883:173372-87.

12 Sanders JM, Monogue ML, Jodlowski TZ, Cutrell JB. Pharmacologic treatments for coronavirus disease 2019 (COVID-19): a review. JAMA. 2020.

13 Chandra A, Gurjar V, Qamar I, Singh N. Identification of potential inhibitors of SARSCOV-2 endoribonuclease (EndoU) from FDA approved drugs: a drug repurposing approach to find therapeutics for COVID-19. J Biomol Struct Dyn. 2020:1.

14 Shanga J, Wana Y, Luoa C, Yea G, Genga Q, Auerbacha A, et al. Cell entry mechanisms of SARS-CoV-2. Proc Natl Acad Sci U S A. 2020; 117(21):11727-34.

15 Almerie MQ, Kerrigan DD. The association between obesity and poor outcome after COVID-19 indicates a potential therapeutic role for montelukast. Med Hypotheses. 2020;143: 109883.

16 Funk CD, Ardakani A. A novel strategy to mitigate the hyperinflammatory response to COVID-19 by targeting leukotrienes. Front Pharmacol. 2020;11:1214.

17 Barré J, Sabatier JM, Annweiler C. Montelukast drug may improve COVID-19 prognosis: a review of evidence. Front Pharmacol. 2020; 11:1344.

18 Bozek A, Winterstein J. Montelukast's ability to fight COVID-19 infection. J Asthma. 2020; $17: 1-2$.

19 Khan AR, Misdary C, Yegya-Raman N, Kim S, Narayanan N, Siddiqui S, et al. Montelukast in hospitalized patients diagnosed with COVID-19. J Asthma. 2021:1.

20 Sanders CJ, Vogel P, McClaren JL, Bajracharya $\mathrm{R}$, Doherty PC, Thomas PG. Compromised respiratory function in lethal influenza infection is characterized by the depletion of type I alveolar epithelial cells beyond threshold levels. Am J Physiol Lung Cell Mol Physiol. 2013;304(7):L481-8.

21 Brandes M, Klauschen F, Kuchen S, Germain RN. A systems analysis identifies a feedforward inflammatory circuit leading to lethal influenza infection. Cell. 2013;154(1):197212.

22 Cardani A, Boulton A, Kim TS, Braciale TJ. Alveolar macrophages prevent lethal influenza pneumonia by inhibiting infection of type1 alveolar epithelial cells. PLoS Pathog. 2017; 13(1):e1006140-25.

23 Landeras-Bueno S, Fernández Y, Falcón A, Oliveros JC, Ortín J. Chemical genomics identifies the PERK-mediated unfolded protein stress response as a cellular target for influenza virus inhibition. mBio. 2016; 7: e00085-16.

24 Chen Y, Li Y, Wang X, Zou P. Montelukast, an anti-asthmatic drug, inhibits Zika virus infection by disrupting viral integrity. Front Microbiol. 2020;10:3079.

25 Costela-Ruiz VJ, Illescas-Montes R, PuertaPuerta JM, Ruiz C, Melguizo-Rodríguez L. SARS-CoV-2 infection: the role of cytokines in COVID-19 disease. Cytokine Growth Factor Rev. 2020;54:62-75.

26 Fitzgerald D, Mellis C. Leukotriene receptor antagonists in virus-induced wheezing: evidence to date. Treat Respir Med. 2006;5(6): 407-17.

27 Wu AY, Chik SC, Chan AW, Li Z, Tsang KW, Li W. Anti-inflammatory effects of high-dose montelukast in an animal model of acute asthma. Clin Exp Allergy. 2003;33(3):359-66.

28 Fidan C, Aydoğdu A. As a potential treatment of COVID-19: montelukast. Med Hypotheses. 2020;142(109828):109828.

29 Tortorici MA, Veesler D. Structural insights into coronavirus entry. Adv Virus Res. 2019; 105:93-116. 
30 Brielle ES, Schneidman-Duhovny D, Linial M. The SARS-CoV-2 exerts a distinctive strategy for interacting with the ACE2 human receptor. Viruses. 2020;12(5):497.

31 Chen CY, Deng QX, Dai SQ. Remdesivir for severe acute respiratory syndrome coronavirus 2 causing COVID-19: an evaluation of the evidence. Travel Med Infect Dis. 2020;35: 101647.

32 Singh RK, Gupta S, Dastidar S, Ray A. Cysteinyl leukotrienes and their receptors: molecular and functional characteristics. Pharmacology. 2010;85(6):336-49.

33 Singh RK, Tandon R, Dastidar SG, Ray A. A review on leukotrienes and their receptors with reference to asthma. J Asthma. 2013; 50(9):922-31.

34 Singh RK. Antagonism of cysteinyl leukotrienes and their receptors as a neuroinflammatory target in Alzheimer's disease. Neurol Sci. 2020;41:2081-93.

35 Li S, Jiang L, Li X, Lin F, Wang Y, Li B, et al. Clinical and pathological investigation of patients with severe COVID-19. JCI Insight. 2020;5(12):e138070.

36 Zhang X, Tan Y, Ling Y, Lu G, Liu F, Yi Z, et al. Viral and host factors related to the clinical outcome of COVID-19. Nature. 2020;583: $437-40$.

37 Wong CK, Lam CW, Wu AK, Ip WK, Lee NL, Chan IH, et al. Plasma inflammatory cytokines and chemokines in severe acute respiratory syndrome. Clin Exp Immunol. 2004; 136(1):95-103

38 Zhang JJ, Dong X, Cao YY, Yuan YD, Yang $\mathrm{YB}$, Yan YQ, et al. Clinical characteristics of 140 patients infected with SARS-CoV-2 in Wuhan, China. Eur J Allergy Clin Immunol. 2020;75(7):1730-41.

39 Lu X, Pan J, Tao J, Guo D. SARS-CoV nucleocapsid protein antagonizes IFN- $\beta$ response by targeting initial step of IFN- $\beta$ induction pathway, and its $\mathrm{C}$-terminal region is critical for the antagonism. Virus Genes. 2011;42(1):3745.

40 Polak SB, van Gool IC, Cohen D, van der Thüsen JH, van Paassen J. A systematic review of pathological findings in COVID-19: a pathophysiological timeline and possible mechanisms of disease progression. Modern Pathology. 2020 June.

41 Ganji A, Farahani I, Khansarinejad B, Ghazavi A, Mosayebi G. Increased expression of CD8 marker on T-cells in COVID-19 patients. Blood Cells Mol Dis. 2020;83:102437.
42 Channappanavar R, Perlman S. Pathogenic human coronavirus infections: causes and consequences of cytokine storm and immunopathology. Semin Immunopathol. 2017; 39(5):529-39.

43 Diao B, Wang C, Tan Y, Chen X, Liu Y, Ning $\mathrm{L}$, et al. Reduction and functional exhaustion of $\mathrm{T}$ cells in patients with coronavirus disease 2019 (COVID-19). Front Immunol. 2020;11: 827.

44 Liu R, Wang Y, Li J, Han H, Xia Z, Liu F, et al. Decreased $T$ cell populations contribute to the increased severity of COVID-19. Clin Chim Acta. 2020;508:110-4.

45 Weiskopf D, Schmitz KS, Raadsen MP, Grifoni A, Okba NMA, Endeman H, et al. Phenotype and kinetics of SARS-CoV-2-specific T cells in COVID-19 patients with acute respiratory distress syndrome. Sci Immunol. 2020; 5(48):eabd2071.

46 Coskun AK, Yigiter M, Oral A, Odabasoglu F, Halici Z, Mentes O, et al. The effects of montelukast on antioxidant enzymes and proinflammatory cytokines on the heart, liver, lungs, and kidneys in a rat model of cecal ligation and puncture-induced sepsis. ScientificWorldJournal. 2011;11:1341-56.

47 Liu J, Li S, Liu J, Liang B, Wang X, Wang H, et al. Longitudinal characteristics of lymphocyte responses and cytokine profiles in the peripheral blood of SARS-CoV-2 infected patients. EBioMedicine. 2020;55:102763.

48 Anastasiou I, Eleftheriadou I, Tentolouris A, Tsilingiris $\mathrm{D}$, Tentolouris $\mathrm{N}$. In vitro data of current therapies for SARS-CoV-2. Curr Med Chem. 2020;27(27):4542.

49 Wu AY, Chik SC, Chan AW, Li Z, Tsang KW, Li W. Anti-inflammatory effects of high-dose montelukast in an animal model of acute asthma. Clin Exp Allergy. 2003;33(3):359-66.

50 Copertino DC, Duarte RRR, Powell TR, Rougvie MM, Nixon DF. Montelukast drug activity and potential against severe acute respiratory syndrome coronavirus 2 (SARSCoV-2). J Med Virol. 2020.

$51 \mathrm{Qu}$ X, Chen Y, Yin C. Effect of montelukast on the expression of CD4+CD25+ regulatory $\mathrm{T}$ cells in children with acute bronchial asthma. Exp Ther Med. 2018;16:2381-6.
52 Conti P, Ronconi G, Caraffa A, Gallenga CE Ross R, Frydas I, et al. Induction of pro-inflammatory cytokines (IL-1 and IL-6) and lung inflammation by Coronavirus-19 (COVI-19 or SARS-CoV-2): anti-inflammatory strategies. J Biol Regul Homeost Agents. 2020;34(2):327

53 Peters-Golden M, Gleason MM, Togias A. Cysteinyl leukotrienes: multi-functional mediators in allergic rhinitis. Clin Exp Allergy. 2006;36(6):689-703.

54 Chen Y, Li Y, Wang X, Zou P. Montelukast, an anti-asthmatic drug, inhibits Zika virus infection by disrupting viral integrity. Front $\mathrm{Mi}-$ crobiol. 2020;10:3079-14.

55 Farag AB, Wang P, Ahmed MS, Sadek HA. Identification of FDA approved drugs targeting COVID-19 virus by structure-based drug repositioning. ChemRxiv. 2020

56 Wu C, Liu Y, Yang Y, Zhang P, Zhong W, Wang Y, et al. Analysis of therapeutic targets for SARS-CoV-2 and discovery of potential drugs by computational methods. Acta Pharm Sin B. 2020;10(5):766-88.

57 Calya L, Drucea JD, Cattona MG, Jansb DA, Wagstaffb MK. The FDA-approved drug ivermectin inhibits the replication of SARSCoV-2 in vitro. Antiviral Res. 2020;178: 104787.

58 Gupta D, Sahoo AK, Singh A. Ivermectin: potential candidate for the treatment of Covid 19. Braz J Infect Dis. 2020;24(4):369-71.

59 Bleyzac N, Goutelle S, Bourguignon L, Tod M. Azithromycin for COVID-19: more than just an antimicrobial? Clin Drug Investig. 2020; 40:683-6.

60 Damle B, Vourvahis M, Wang E, Leaney J, Corrigan B. Clinical pharmacology perspectives on the antiviral activity of azithromycin and use in COVID-19. Clin Pharmacol Ther. 2020;108(2):201-11.

61 Jean SS, Lee PI, Hsueh PR. Treatment options for COVID-19: the reality and challenges. J Microbiol Immunol Infect. 2020;53(3):43643.

62 Bianconi V, Violi F, Fallarino F, Pignatelli P, Sahebkar A, Pirro M. Is acetylsalicylic acid a safe and potentially useful choice for adult patients with COVID-19? Drugs. 2020;80(14): 1383-96.

63 Hoxha M, Lewis-Mikhael AM, Bueno-Cavanillas A. Potential role of leukotriene receptor antagonists in reducing cardiovascular and cerbrovascular risk: a systematic review of human clinical trials and in vivo animal studies. Biomed Pharmacother. 2018;106:956-65. 